\title{
The preoperatively normal bile duct does not dilate after cholecystectomy: results of a five year study
}

\author{
A W Majeed, B Ross, A G Johnson
}

\begin{abstract}
Background-The common hepatic duct (CHD) is commonly believed to dilate after cholecystectomy but previous studies have either not measured CHD diameter preoperatively or the follow up period is short.

Aims-To measure CHD diameter before and after cholecystectomy.

Methods-Patients undergoing (open) cholecystectomy and operative cholangiography had ultrasonographic measurement of CHD diameter before, and three and six months, and one and five years after cholecystectomy. The normal duct diameter was considered to be $5 \mathrm{~mm}$ or less, with an observer error of $\pm 1 \mathrm{~mm}$.

Results-Fifty nine patients with normal diameter ducts were studied. The majority (more than $95 \%$ ) of patients did not have a dilatation of the CHD beyond $6 \mathrm{~mm}$ after cholecystectomy. The CHD appeared to increase as well as decrease with an overall trend towards a minor increase at five years. This was not statistically significant if the margin of error of $1 \mathrm{~mm}$ was taken into account.

Conclusion-A preoperatively normal CHD does not dilate after cholecystectomy and may require further investigation in symptomatic patients.

(Gut 1999;45:741-743)
\end{abstract}

Keywords: common hepatic duct; ultrasonography; cholecystectomy; bile duct dilatation

In 1890 , Oddi postulated that the common duct would dilate after cholecystectomy as it would take over the reservoir function of the gall bladder. Subsequent autopsy evidence ${ }^{1}$ collected by early investigators substantiated this theory and the hypothesis came to be accepted as fact, despite absence of preoperative diameters. The introduction of intravenous cholangiography allowed common duct imaging in post-cholecystectomy patients and studies of common duct size did not support the hypothesis; in fact some studies showed that the common duct either remains the same or reduces in size after cholecystectomy. ${ }^{2}{ }^{3}$ Soon after its introduction, ultrasonography rapidly became accepted to be the most sensitive method of measurement of common hepatic and common bile duct diameter, ${ }^{4}$ and many prospective studies showed that while the majority of patients did not have a significant increase in diameter of the common hepatic duct (CHD) after cholecystectomy, there was a trend towards a minor degree of duct dilatation. ${ }^{5-7}$ Patients who suffer from postcholecystectomy symptoms are an important group where common duct dilatation might be an indication for further invasive investigations (for example, endoscopic retrograde cholangiopancreatography, ERCP) and it is therefore important to establish the range of CHD diameters which might be considered normal after cholecystectomy.

We report a prospective series of patients with normal (less than $5 \mathrm{~mm}$ ) common hepatic ducts who underwent ultrasonographic measurement of the CHD by a single experienced radiologist before cholecystectomy and subsequently at three months, six months, one year, and five years after cholecystectomy. Patients who had dilated (greater than $5 \mathrm{~mm}$ ) ducts before cholecystectomy were excluded from the study.

\section{Patients and methods}

The study was conducted on patients who underwent open cholecystectomy for symptomatic cholelithiasis between 1984 and 1988 . These patients were participating in the Sheffield randomised trial comparing cholecystectomy and shock wave lithotripsy and had all been randomised to the cholecystectomy arm of the trial.

Patients with a history of liver damage (or abnormal liver function tests), jaundice, pancreatitis, non-emptying (less than $50 \%$ of fasting volume) gall bladder after fatty meal stimulation, preoperative common duct dilatation (CHD diameter greater than $5 \mathrm{~mm}$ ), abnormal clotting, or current pregnancy were excluded from the study. All patients underwent routine peroperative cholangiography and if unexpected stones were found, they were excluded from analysis.

Ultrasonographic measurement of the CHD was carried out by a single experienced radiologist (BR). The same ultrasound machine (Combison 310, Kretz Technik, Austria) with a $3.5 \mathrm{MHZ}$ oscillating probe was used in all cases. Measurement of the CHD was carried out before surgery and subsequently at three months, six months, one year, and five years after open cholecystectomy (with routine operative cholangiography). CHD diameter was measured at the level of the porta hepatis in all patients and results are expressed in

Abbreviations used in this paper: $\mathrm{CHD}$, common hepatic duct; ERCP, endoscopic retrograde cholangiopancreatography. 


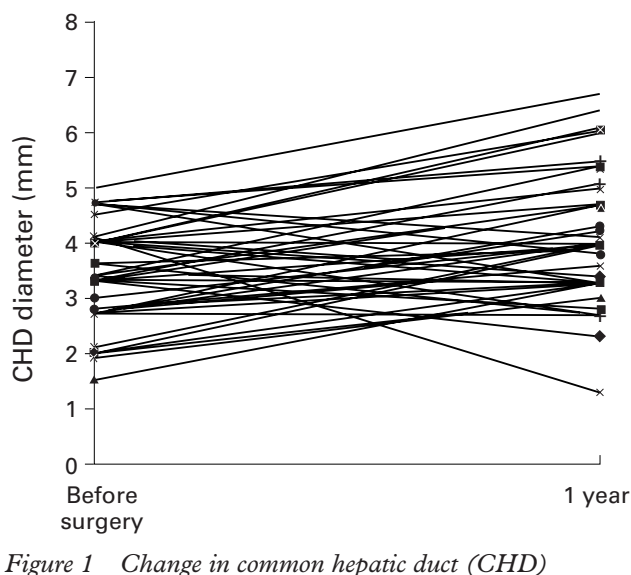

Figure 1 Change in common hepatic duct (CHD) diameter at one year.

millimetres. The measurement error for ultrasonography of the common hepatic duct was defined as $\pm 1 \mathrm{~mm}$.

\section{Results}

Fifty nine patients (43 women and 16 men) were studied. Median age was 56 years (range 25-77 years) at the time of inclusion into the study. A total of $39(66 \%), 49(83 \%), 58$ $(98 \%)$, and $48(81 \%)$ patients attended for follow up scanning at three months, six months, one year, and five years, respectively.

\section{PREOPERATIVE}

All patients had a preoperative ductal diameter less than $5.0 \mathrm{~mm}$. During cholecystectomy, five patients had suspected filling defects on routine operative cholangiography; however, subsequent common duct exploration and choledochoscopy showed common duct stones in only one patient who was excluded from analysis.

\section{THREE MONTHS}

Of the 39 patients who attended for scanning at three months, $35(89.7 \%)$ had common duct diameter $5 \mathrm{~mm}$ or less. Four patients $(10.2 \%)$ had a duct size of $5.1-6.0 \mathrm{~mm}$ (within measurement error of ultrasonography) and no patient had a duct diameter greater than $6.0 \mathrm{~mm}$.

SIX MONTHS

Of the 49 patients who attended for scanning at six months, $43(87.7 \%)$ had common duct diameter $5 \mathrm{~mm}$ or less. Three patients $(6.1 \%)$ had a duct size of $5.1-6.0 \mathrm{~mm}$ and three $(6.1 \%)$ had a duct diameter greater than $6.0 \mathrm{~mm}$

Table 1 Patient numbers and bile duct diameter three months to five years after cholecystectomy

\begin{tabular}{lllll}
\hline \multicolumn{5}{c}{ Diameter } \\
\cline { 3 - 5 } & $n$ & $\leqslant 5 m m$ & $5.1-6.0 \mathrm{~mm}$ & $>6.0 \mathrm{~mm}$ \\
\hline Preoperative & 59 & 59 & 0 & 0 \\
3 months & 39 & $35(89.7 \%)$ & $4(10.2 \%)$ & 0 \\
6 months & 49 & $43(87.7 \%)$ & $3(6.1 \%)$ & $3(6.1 \%)$ \\
1 year & 58 & $49(84.4 \%)$ & $6(10.3 \%)$ & $3(5.1 \%)$ \\
5 years & 48 & $41(85.4 \%)$ & $5(10.4 \%)$ & $1(2.1 \%)$ \\
\hline
\end{tabular}

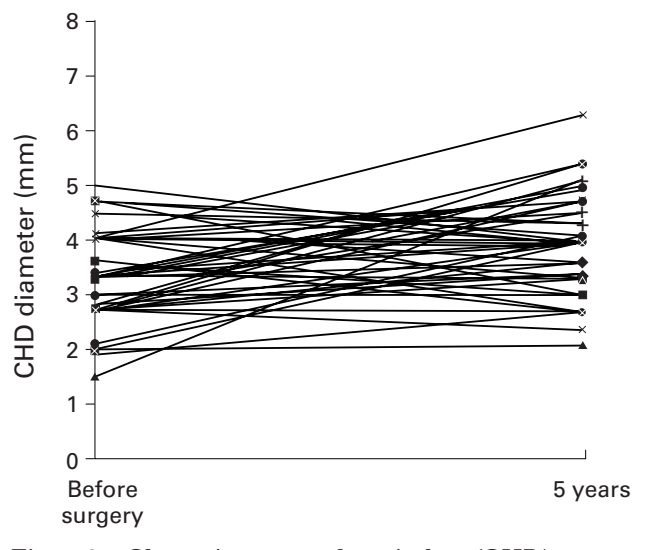

Figure 2 Change in common hepatic duct (CHD) diameter at five years.

ONE YEAR

Of the 58 patients who attended for scanning at one year, $49(84.4 \%)$ had common duct diameter $5 \mathrm{~mm}$ or less (fig 1). Six patients $(10.3 \%)$ had a duct size of $5.1-6.0 \mathrm{~mm}$ and only three $(5.1 \%)$ had a duct diameter greater than $6.0 \mathrm{~mm}$.

\section{FIVE YEARS}

Of the 48 patients who attended for scanning at five years, $41(85.4 \%)$ had common duct diameter $5 \mathrm{~mm}$ or less (fig 2). Five patients $(10.4 \%)$ had a duct size of 5.1-6.0 mm (which lies within the measurement error of ultrasonography). Only one patient had a duct diameter greater than $6.0 \mathrm{~mm}$. There was no correlation between duct diameter at five years and age (Spearman's rank correlation test: $\left.r_{\mathrm{S}}=0.01, \mathrm{p}=0.94\right)$ or $\operatorname{sex}\left(r_{\mathrm{s}}=-0.03, \mathrm{p}=0.81\right)$.

CHANGES IN MEAN DIAMETER

The mean (SD) CHD diameter of all patients before cholecystectomy was $3.43(0.82) \mathrm{cm}$. This changed to $3.78(0.87) \mathrm{cm}$ at three months, $3.76(1.16) \mathrm{cm}$ at six months, 3.95 $(1.06) \mathrm{cm}$ at one year, and $3.96(1.11) \mathrm{cm}$ at five years. The difference between preoperative duct diameter and diameter at six months, one year, and five years was statistically significant using a paired $t$ test, although this difference disappeared when the margin of error of $1 \mathrm{~mm}$ was considered. The clinical relevance of such a minor increase is also dubious.

\section{Discussion}

The issue of CHD dilatation after cholecystectomy is important because significant pathology might be missed if ultrasonographic detection of such a dilatation is attributed to "expected" post-cholecystectomy appearances. The one previous report of patients scanned before and five years after cholecystectomy included only 24 patients and reported a "strong trend" towards minor dilatation with a mean increase from $3.95 \mathrm{~mm}$ to $4.48 \mathrm{~mm}$. The observer error of ultrasonographic measurement is known to be $1-2 \mathrm{~mm}^{8}$ and even respiratory variation exceeding $1 \mathrm{~mm}$ has been observed. ${ }^{9}$ If these variations are taken into account, the mean increase of $0.53 \mathrm{~mm}$ is well within this error. Another report of 673 normal 
controls whose bile duct width was compared with post-cholecystectomy patients showed a difference of $0.8 \mathrm{~mm}$.

Increasing age has been implicated as a factor in bile duct dilatation, ${ }^{10}{ }^{11}$ but most studies of age related change do not employ ultrasonography; those that do show only minor changes. ${ }^{12}$ A recent review of the subject ${ }^{13}$ suggests that infusion cholangiography may be a more sensitive method of measuring bile duct width. However, this technique is not commonly used due to a risk of adverse reaction to the contrast medium, and its accuracy is doubtful due to the choleretic effect of the infusion which in itself might cause biliary distension. More importantly, the magnification effect of $x$ rays may increase the margin of error of measurement. ${ }^{14}$ A comparison of bile duct diameter in post-cholecystectomy patients undergoing ERCP with controls ${ }^{15}$ suggested that the post-cholecystectomy bile ducts may be wider than normal; however, this study did not examine the patients preoperatively and did not take into account the possible increased distensibility of the common duct after cholecystectomy, ${ }^{16}{ }^{17}$ which may be accentuated during injection at ERCP.

All patients in our study had "functioning" gall bladders (gall bladders which contracted $50 \%$ or more of their resting volume after fatty meal stimulation) and were possibly a selected group with no inflammation. Conceivably, this is the group in which the "function" of bile storage would likely have been taken over by the common bile duct; these patients would therefore be more likely to have duct dilatation, a hypothesis which is not borne out by our results.

We conclude that if a margin of error of $1 \mathrm{~mm}$ for ultrasonographic measurement of the $\mathrm{CHD}$ is taken into account, the diameter of the common duct does not change significantly after cholecystectomy. Increase in diameter beyond $6 \mathrm{~mm}$ on ultrasonography (of ducts which were preoperatively "normal" that is, $5 \pm 1 \mathrm{~mm}$ or less in diameter) should therefore be considered an indication for further imaging of the common duct. The morbidity of ERCP might make this difficult to justify, but the advent of magnetic resonance cholangiography would allow a non-invasive assessment of the common hepatic and common bile ducts.

1 Peustow C, Morrison R. The relationship of cholecystitis and cholecystectomy to dilatation of the choledochus. Ann Surg 1935;101:599-602.

2 Gylstorff H, Faber H. Choledochus changes after cholecystectomy (pre- and postoperative examination of 400 patients). Acta Chir Scand 1963;125:499-501.

3 Hughes J, LoCurcio S, Edmunds R, et al. The common duct after cholecystectomy. $¥ A M A$ 1966;197:247-50.

4 Parulekar SG. Ultrasound evaluation of common bile duct size. Radiology 1979;133:703-7.

5 Hunt DR, Scott AJ. Changes in bile duct diameter after Hunt DR, Scott AJ. Changes in bile duct diameter after
cholecystectomy: a 5-year prospective study. Gastroenterolcholecystectomy: a 5-ye

6 Hammarstrom LE, Holmin T, Stridbeck H, et al. Routine preoperative infusion cholangiography at elective cholecystectomy: a prospective study in 694 patients. $\mathrm{Br} \mathcal{F}$ Surg 1996;83:750-4

7 Bruneton JN, Roux P, Fenart D, et al. Ultrasound evaluation of common bile duct size in normal adult patients and following cholecystectomy. A report of 750 cases. Eur 7 Radiol 1981;1:171-2.

8 Niederau C, Sonnenberg A, Mueller J. Comparison of the extrahepatic bile duct size measured by ultrasound and by different radiographic methods. Gastroenterology 1984;87: 615-21.

9 Wachsberg RH. Respiratory variation of extrahepatic bile duct diameter during ultrasonography. $f$ Ultrasound Med 1994;13:617-21.

10 Mahour G, Wakim K, Ferris D. The common bile duct in man: its diameter and circumference. Ann Surg 1967;165: man: its

11 Edholm P, Jonsson G. Bile duct stones related to age and duct width. Acta Chir Scand 1962;124:75-9.

12 Wu CC, Ho YH, Chen CY. Effect of aging on common bile duct diameter: a real-time ultrasonographic study. $₹ \mathrm{Clin}$ Ultrasound 1984;12:473-8.

13 Hammarstrom LE. Is there a significant increase in bile duct width after cholecystectomy? Scand $\mathcal{F}$ Gastroenterol 1997; 32:961-4

14 Sauerbrei EE, Cooperberg PL, Gordon P, et al. The discrepancy between radiographic and sonographic bile-duct measurements. Radiology 1980;137:751-5.

15 Hamilton I, Ruddell WS, Mitchell CJ, et al. Endoscopic retrograde cholangiograms of the normal and postcholecystectomy biliary tree. Br F Surg 1982;69:343-5.

16 Mueller PR, Ferrucci JT, Simeone JF, et al. Observations on the distensibility of the common bile duct. Radiology 1982; 142:467-72.

17 Morgan B, Rathod A, Crozier A, et al. Biliary distensibility during per-operative cholangiography as compared with pre-operative ultrasound: a four year follow-up study. Clin Radiol 1996;51:338-40. 